\title{
Emotional valence and the functions of autobiographical memories: Positive and negative memories serve different functions
}

\author{
AnNe S. Rasmussen and Dorthe Berntsen \\ Aarhus University, Aarhus, Denmark
}

\begin{abstract}
Differences between positive and negative autobiographical memories are often explained with reference to hypothesized evolutionary functions. Generally, it has been proposed that autobiographical memory serves directive, self-, and social functions. However, the relationship between emotional valence and the three functions has never been studied. In Study 1, participants generated memories that mapped onto each of the three functions. Directive memories were dominated by negative emotion, whereas self- and social memories were dominated by positive emotion. In Study 2, participants generated their most positive and most negative memories, as well as their most frequent involuntary and most vivid flashbulb memories, and the three functions were measured through rating-scale questions. The directive function had the lowest ratings across all memory classes, but, consistent with the results of Study 1, positive memories were rated higher on the self- and social functions, whereas negative memories were rated higher on the directive function.
\end{abstract}

When memory researchers attempt to explain why certain classes or types of autobiographical memories differ from others, they often make reference to hypothesized functions of the memories. For example, it is often assumed that autobiographical memory has evolved in order to serve distinct self-related functions (see, e.g., Baddeley, 1988; James, 1890/1950; Neisser, 1982a), and that emotionally negative memories contain information that is more crucial to our survival than emotionally positive memories, for which reason the two classes of memories also differ regarding other characteristics (see, e.g., Freud, 1920/1952; Talarico, Berntsen, \& Rubin, 2009; Taylor, 1991). Although references to such hypothesized evolutionary functions are frequent in the literature, surprisingly little research has been conducted to assess their validity. In the present article, we report two studies designed to remedy this shortcoming. We define function as the real-world usefulness and adaptive significance of autobiographical memories (Bruce, 1989, p. 45), and we pursue the hypothesis that different classes of memories serve different functions.

According to several researchers (e.g., Bluck, 2003; Cohen, 1998; Pillemer, 1992), autobiographical memory function can be summarized in terms of three broad categories: Directive (instrumental and guiding behavior), self (self-concept and self-continuity), and social (communicative and social bonding). However, this model does not specify how different classes of autobiographical memories may serve different functions. For instance, research has shown consistent differences between the char- acteristics of emotionally positive and negative memories (see, e.g., Bohn \& Berntsen, 2007; Walker, Skowronski, $\&$ Thompson, 2003). It has been suggested that negative memories signal danger and the need for immediate reaction (e.g., Levine \& Bluck, 2004; Taylor, 1991), whereas positive memories may have broader and more constructive uses (Fredrickson \& Branigan, 2005). Consequently, positive and negative memories should differ on the three above-mentioned functions. However, this possibility has not been examined systematically.

In the present two studies, we examined memory characteristics associated with different functions of autobiographical memories, and in particular whether emotionally positive and negative memories serve different functions. Because it is likely that any autobiographical memory may serve multiple functions, our goal was to examine the relative dominance of different functions in different classes of memories. We will first describe the conceptual framework guiding our studies on functional differences. We will then delineate the theoretical background for our basic predictions regarding functional differences between positive and negative memories.

\section{A Functional Approach to Autobiographical Memory: Directive, Self-, and Social Functions}

Several researchers have argued in favor of a functional approach to autobiographical memory (e.g., Baddeley, 1988; Bruce, 1985, 1989; Glenberg, 1997; Nairne \& Pandeirada, 2008; Neisser, 1982a), but empirical research has been rather limited until recently (see Bluck, Alea,

A. S. Rasmussen, annesr@psy.au.dk 
Habermas, \& Rubin, 2005, for a review). Three functions have been mentioned repeatedly in the literature (e.g., Pillemer, 1992). In the present article, we adapt the terminology provided by Bluck and Alea (2002) and we refer to memories that are dominant on one of the three functions as directive, self-, and social memories.

The directive function of autobiographical memory guides present and future thinking and behavior (Pillemer, 1998). Memories with directive functions assist in problem solving and planning (Baddeley, 1988; Cohen, 1998), and they also inspire, inform, and motivate (Pillemer, 2003). Thus, there seem to be two aspects of the directive function: One is merely instrumental in a nonself-referential way (e.g., when a memory of last year's New Year's celebration tells you what to bring for this year's party), whereas the other is more self-related (e.g., when the memory of an inspiring meeting with a leading researcher becomes the originating point for a research career). Pillemer (2003) argued that the directive function is the most basic and evolutionarily earliest of the three functions. He speculated that automatic (i.e., involuntary and spontaneous) retrieval may be especially closely associated with directive memories because of the obvious benefits of skipping more time-demanding strategic retrieval in situations that call for immediate instrumental actions - such as getting away from danger. Consequently, directive memories may be harder to identify through strategic (i.e., voluntary and goal-directed) recall than self- or social memories.

The self-function of autobiographical memory is inherent in many theories of autobiographical memory (see, e.g., Bluck \& Habermas, 2000; Conway \& PleydellPearce, 2000; James, 1890/1950). Indeed, autobiographical memory has been defined as memory related to the self (e.g., Brewer, 1986, 1996). Furthermore, it has been suggested that autobiographical memory should be conceptually limited to memories that are self-defining (Neisser, 1982a), self-relevant (Pillemer, 2001), or that constitute the self-concept (Baddeley, 1988; Cohen, 1998; Fivush, 1988). The maintenance of self-continuity is thought to be one of the more important self-functions (Bluck et al., 2005; Conway, 1996). Because of their central status to personal identity, self-memories may become highly accessible reference points for the attribution of meaning to other autobiographical memories (Berntsen \& Rubin, 2006, 2007) and are thus subject to more purposeful or goal-directed rehearsal than directive or social memories.

The social function is apparent when individuals share their memories with others in order to persuade, ease communication, facilitate social bonding, and elicit empathy or intimacy (see, e.g., Alea \& Bluck, 2007b; Cohen, 1998; Pillemer, 1992). Although some researchers have suggested that memories may also serve intimacy functions - even if they are not shared with others (Alea \& Bluck, 2003, 2007b) - we define social memories as memories that are often shared. We choose this definition because memory sharing is theorized to be one of the primary functions of autobiographical memory (e.g., Nelson, 1993), and because this definition minimizes conceptual overlap with the two other functions. Hence, by definition, social memories should be more frequently shared in conversation than directive or self-memories. On the other hand, they might not be subject to as much private rehearsal as directive or self-memories.

Some researchers have pointed out that the tripartite model may not apply to episodes of specific recall, because individual memories often serve functions in more than one category (see, e.g., Conway, 2003). One way of addressing this concern is to consider the presence of each function as a matter of degree rather than as a binary decision. Others have proposed possible relations between the three functions and basic memory characteristics, such as content, emotional valence, or accessibility of the memories (e.g., Bluck \& Alea, 2002; Hyman \& Faries, 1992), suggesting that different types of memories may serve some functions more than others. However, very little research has been conducted in order to clarify this matter. For instance, in two survey studies, Bluck and colleagues (Alea \& Bluck, 2007a; Bluck et al., 2005) found support for all three functions in people's self-reported uses of autobiographical memory, but did not measure the functions of concrete memories. Wong and Watt (1991) classified memories of significant life events reported in an older sample according to function. They found that the social function was the most dominant, but they also found support for the self- and directive functions. Although this study examined the functions of concrete memories, different classes of memories (e.g., positive vs. negative memories) were not compared. Hyman and Faries examined people's self-reported use of the three functions in memories that were frequently talked about and memories that were elicited in response to neutral word cues. Results supported the idea that the social and self-functions were associated with both memory types, whereas evidence for the directive function was not found in any of the conditions. However, retrospective reports may underestimate the actual frequency of the directive function, since directive memories may be harder to access through strategic recall, as argued earlier (Pillemer, 2003). Pasupathi, Lucas, and Coombs (2002) coded memories appearing in long-married couples' conversations about conflict and pleasant topics and found support for all three functions, although the directive function was more frequent in conversations involving conflict. Wood and M. Conway (2006, as discussed in Wood, 2006) examined the self-reported uses of memories elicited in response to nine discrete emotions (happiness, love, pride, shame, embarrassment, anger, fear, sadness, guilt) and found support for all three functions, but no definitive relationship between function and emotion. Finally, in a recent study, McLean and Lilgendahl (2008) examined memories of high and low points in the life stories of younger and older adults and found that memories of high points were rated higher on self- and social functions than memories of low points. However, they did not measure the directive function, emotional valence, or other basic characteristics of the memories.

In summary, empirical research yields consistent support for all three functions of autobiographical memories, and 
some studies also suggest that different classes of memories may serve different functions (e.g., McLean \& Lilgendahl, 2008; Pasupathi et al., 2002). However, the three functions have not been studied systematically in relation to specific recollections and their associated emotional valence, accessibility, and other basic characteristics.

\section{Hypothesized Evolutionary Functions of Positive and Negative Memories}

Although research across many areas of psychological functioning shows that people pay more attention to negative than to positive information (see, e.g., Baumeister, Bratslavsky, Finkenauer, \& Vohs, 2001; Taylor, 1991; Vaish, Grossmann, \& Woodward, 2008), autobiographical memory is usually biased in favor of pleasant information (Walker et al., 2003). Furthermore, a number of studies have provided evidence that positive memories are associated with more contextual detail than negative memories, whereas negative memories tend to be more accurate (see, e.g., Levine \& Pizarro, 2004, for a review). Such differences have been explained with reference to hypothesized evolutionary benefits of remembering different aspects of positive versus negative events, such as maintaining a positive self-image versus optimizing personal survival, respectively (e.g., Bohn \& Berntsen, 2007; Christianson, 1992; Fredrickson, 1998; Levine \& Bluck, 2004; Talarico et al., 2009; Taylor, 1991). If such assumptions are valid, we should expect people's subjective assessments of memory functions to show systematic differences between positive and negative memories. However, this possibility has never been examined systematically in relation to all three functions.

Taylor and Brown (1988) observed that human thought is biased in a positive direction characterized by an overly positive self-concept, an exaggerated perception of personal control, and an unrealistic optimism for the future. They further argued that this is adaptive from an evolutionary perspective, because these biases are associated with characteristics that promote mental health and wellbeing (Taylor, 1991; Taylor \& Brown, 1988). Research suggests that autobiographical memory works in a similar manner by overrepresenting positive events and by dampening the emotional and phenomenological reliving associated with negative memories (see, e.g., Bohn \& Berntsen, 2007; D'Argembeau \& Van der Linden, 2004; Walker et al., 2003). For instance, people generally perceive more events in their lives to be positive than negative. This pleasantness bias is fairly stable, with people reporting roughly twice as many positive than negative events over a broad range of memory types and studies. Furthermore, the disruption of the general pleasantness bias is associated with mild depression (see Walker et al., 2003 , for a review), suggesting that one of its primary functions is to promote mental well-being. In further support of this possibility, studies show that the integration of a traumatic event into one's personal identity and life story is associated with depression and posttraumatic stress disorder (PTSD; Berntsen \& Rubin, 2006, 2007). There is also evidence that specific memories of positive events have a self-enhancing function (e.g., Wilson
\& Ross, 2003). Negative events are remembered as being more distant in subjective time than positive events (e.g., Ross \& Wilson, 2002, 2003), suggesting that positive memories are kept closer and thus more relevant to the current self than negative memories (Wilson \& Ross, 2003). Finally, positive memories are reported as having a greater impact on how people currently feel about themselves than that of negative memories (Collins, Pillemer, Ivcevic, \& Gooze, 2007).

The dampening of negative memories is supported by several studies. The affect intensity of positive memories fades more slowly over time than the affect intensity of negative memories (see, e.g., Walker, Vogl, \& Thompson, 1997), and positive memories are more accessible than negative memories, as measured by shorter response times (e.g., Lishman, 1974) and self-reported ease of recall (Andersson, Boethius, Svirsky, \& Carlberg, 2006; Collins et al., 2007). Furthermore, memories of positive events are generally reported with more clarity and vividness than memories of negative events, and they tend to involve more phenomenological reliving, sensory imagery, and a greater sense of mentally traveling back in time (e.g., Andersson et al., 2006; Berntsen \& Thomsen, 2005; see Bohn \& Berntsen, 2007, for a review). Finally, positive memories are shared more frequently in conversations than negative or traumatic memories (Berntsen \& Thomsen, 2005; Bohn \& Berntsen, 2007; Byrne, Hyman, $\&$ Scott, 2001; Collins et al., 2007), suggesting that positive memories also serve important functions for social bonding.

The pleasantness bias in autobiographical memory thus has obvious benefits, but it can be seen to pose an enigma regarding negative memories: How do people learn from past mistakes, if aspects associated with negative memories are suppressed, dampened, or minimized? According to another view, there is an adaptive value attached to memories of negative events. From this view, negative events are seen as goal discrepant and as indicators of a problem to be solved. Thus, negative events would cause the individual to focus on and encode the aspects of the events that are necessary in order to solve the problem and prevent future mistakes (see, e.g., Berntsen, 2002; Levine \& Bluck, 2004; Taylor, 1991). In contrast, positive events are not seen as goal discrepant, leaving room for the individual to elaborate on and encode broader and less specific aspects of the event that can be used to build enduring personal and social resources, and to promote long-term adaptation (Fredrickson, 2001; Fredrickson \& Branigan, 2005; Talarico et al., 2009). It has been argued that these hypothesized functions of positive and negative memories are reflected in the amount and quality of detail associated with the memories (e.g., Talarico et al., 2009). For instance, people remember more details in general (both accurate and inaccurate) from positive rather than from negative events (Levine \& Bluck, 2004), and it has been reported that negative memories contain more central and less peripheral details than positive memories do (Berntsen, 2002; Talarico et al., 2009). This may suggest that the functions of negative memories are associated with different memory characteristics than the functions of positive memories are. 
In summary, a large amount of empirical evidence suggests the possibility of different evolutionary functions of positive and negative memories. It has been suggested that autobiographical memory in general, and positive memories in particular, serve the overall function of keeping a positive illusion of life and the self. Positive memories may serve the building of personal and social resources, thereby facilitating social bonding, whereas negative memories may serve more instrumental and directive functions. However, these assumptions have never been studied systematically through theoretically derived measures of all three memory functions.

\section{Outline of the Present Studies}

In the present two studies, we examined the validity of the prediction that positive memories are associated with more self- and social function than negative memories are, whereas negative memories are associated with more directive function. We use two strategies. First, in Study 1, we used descriptions of the directive, self-, and social functions as memory cues. We examined emotional valence as well as other characteristics of autobiographical memories recalled in response to each of these three function cues. Following the tripartite model and the literature on emotion and memory, we expected the ensuing three classes of memories to differ systematically and meaningfully on emotional valence, content, response time, and other basic characteristics. Second, consistent with the argument that individual autobiographical memories may serve more than just one function (Conway, 2003), and the related idea that the relevance of each function is a matter of degree, we treated memory functions as dimensions that could be measured via subjective ratings on Likert scales in response to specific recollections (Study 2). In order to examine again whether positive versus negative memories are associated with different functions, we used requests for the participants' most positive and most negative memories as cues. We expected the same pattern of relations between the three functions and emotional valence across the two studies. In order to explore other possible influences on functional differences, we also examined functions of the participants' most frequent involuntary and most vivid flashbulb memories and compared these with the functions of the most positive and negative memories.

\section{STUDY 1}

In Study 1, we compared the three classes of function memories and a control memory on content, response time, memory characteristics, and the centrality of the event for the person's identity and life story. We predicted that the self- and social memories would be rated as more positive than the directive memories, and that the directive memories would be rated as more negative. Under the assumption of lower accessibility of directive memories for voluntary recall, we predicted that they would have longer response times than self- and social memories would. On the basis of the inherent self-relatedness of self-memories, we predicted that they would be rated as more central to the person's identity and life story than directive and social memories, whereas directive memories would be rated higher on consequences than self- and social memories. Furthermore, on the basis of our definition of social memories, we expected them to be more talked about than directive and self-memories. We expected self-memories to be more thought about than directive memories, and directive memories to be more involuntarily thought about than self-memories.

\section{Method}

Participants. There was a total of 120 (77 women and 43 men, mean age 20.72 years, $S D=1.94$, range $18-33$ years) participants. The data were collected in group sessions. Two groups of 73 and 47 Danish folk high school students participated before a psychology lecture at the folk high school. ${ }^{1}$ All participants were informed that their responses were anonymous, and it was clearly stated that they were free to withdraw at any point during the procedure.

Procedure. The participants answered the same questionnaire for all four classes of memories. They were asked to recall three function memories and a control memory in response to cues that were simultaneously presented on a screen and read out loud by the experimenter. The order of the memory cues was randomized between the groups. Participants were equipped with stopwatches. They were instructed to start the stopwatch when presented with the cue and to stop the timing with the first memory that came to mind that fit the cue. The participants noted the response time and a sentence or two to describe the memory. They then moved on to answering a questionnaire concerning memory characteristics and the centrality of the event for the person's identity and life story. They were instructed to keep the memory in mind while answering these questions. This procedure was practiced thoroughly on a memory for a holiday event that was not entered in the data analysis. To prevent possible carryover effects, easy problem-solving tasks were assigned between each memory task. The procedure had been tested in a small pilot study in which participants were instructed to write detailed descriptions of the three function memories. This part of the task was excluded from the final version of the questionnaire, due to time constraints. Examples from the pilot study are presented in the Appendix with permission from the participants.

Cues. In order to generate directive, self-, and social memories, we derived cues on the basis of the tripartite model. The cue for the directive memory was: Try to recall a memory of an event that you think of in order to handle present or future situations. This formulation captured the instrumental as well as the higher order and more selfrelated aspects of the directive function. The cue for the self-memory was: Try to recall a memory of an event that tells you something about your identity. This formulation captured self-continuity as well as relevance to the person's self-concept. The cue for the social memory was: Try to recall a memory of an event that you have often shared with others. This formulation was based on the assumption that the social function involves memory sharing. The cue for the control memory was: Try to recall a memory of a random event from the last week. This formulation was chosen in order to activate a personal memory with a nondistinct function as well as to be comparable in length with the cues for the three function memories.

Content analysis. In order to examine the emotional content of the memories, we first categorized the memory descriptions according to 17 content categories obtained in a different study (Schlagman, Schulz, \& Kvavilashvili, 2006). We used this coding system because it is based on one of the most systematic content analyses of autobiographical memories to date and was derived independent of an interest in memory functions. The categories were: person (i.e., primarily about other people); accidents including injuries and illnesses (i.e., physical stress); stressful events excluding accidents, illnesses, deaths, and funerals (i.e., psychological stress); holidays; conversations; leisure/sports activities (i.e., including hobbies and games); objects/places (i.e., primarily about an object or a place); going out (e.g., going to a pub/dancing); work/university (e.g., ex- 
Table 1

Questions Answered for All Four Classes of Memories in Study 1

\begin{tabular}{|c|c|}
\hline No. & Variable and Question \\
\hline 1. & Physical: The memory triggered a physical reaction (e.g., palpitations, feeling restless, tense, tears, laughter) \\
\hline 2. & Mood: The memory affected my mood \\
\hline 3. & Back in time: The memory made me feel as if I traveled back in time to the actual situation \\
\hline 4. & Vividness: The memory appears vivid and clear \\
\hline 5. & Visual: While remembering the event, I can see it in my mind \\
\hline 6. & Auditory: While remembering the event, I can hear it in my mind \\
\hline 7. & Olfactory: While remembering the event, I can smell and/or taste it in my mind \\
\hline 8. & Setting: While remembering the event, I can recall the physical surroundings \\
\hline 9. & Reliving: While remembering the event, it feels as though I relive it in my mind \\
\hline 10. & Perspective: While remembering the event, it feels as though I see it from a perspective as seen with \\
\hline 11. & Valence: The feelings I experience, as I recall the event are \\
\hline 12. & Intensity: The feelings I experience, as I recall the event, are intense \\
\hline 13. & $\begin{array}{l}\text { Specificity: The memory deals with an event that occurred once on a specific day, or a mixture of similar events from more than } \\
\text { one day }\end{array}$ \\
\hline 14. & Covert: Since it happened, I have thought about the event \\
\hline 15. & Overt: Since it happened, I have talked about the event \\
\hline 16. & Involuntary: Since it happened, the event has popped up in my mind by itself - that is, without me trying to recall it \\
\hline 17. & Age of memory: How old were you when the event occurred? \\
\hline 18. & Belief: I am convinced that the event took place as I remember it \\
\hline 19. & Consequences: The event has had consequences in my life \\
\hline 20. & Coherence: As I recall the event, it seems to come to me as a coherent story (as opposed to incoherent or in flashes) \\
\hline
\end{tabular}

Note-Response options for Questions 1-9, 12, 18-20: 1 = not at all, 7 = to a very high degree. For Questions 14-16: $1=$ almost never $7=$ extremely often. For Question 10: $1=$ my own eyes, $7=$ an observer's eyes. For Question 11: $-3=$ extremely negative, $3=$ extremely positive. For Question 13:1 = specific memory, $0=$ generalized memory. For Question 17: I was__ years. In the analyses (and following tables), age of memory was calculated by subtracting the answer to Question 17 from the person's current age.

periences at work or university); romantic involvement (e.g., being intimate, romantic dinners, receiving gifts for Valentine's Day); school (e.g., experiences at school—including high school and folk high school); deaths/funerals; special occasions (e.g., birthdays, weddings, engagements, parties); births; traveling/journeys; war/ army; and miscellaneous. The coding was carried out in accordance with the guidelines described by Schlagman et al. (2006). We first attempted to classify each memory so that the category captured all of the themes mentioned in the memory description. For example, some descriptions contained a number of themes or activities that could all be classified into the superordinate category of school. If a memory description contained multiple different themes, we based the categorization on the theme that was mentioned first in the description. The first author and an independent rater categorized each memory using these guidelines, and an independent judge decided on the category in case of disagreement. The interrater reliability, as measured by Cohen's $\kappa$, showed good agreement between the two raters (.795 for the directive memory, .798 for the self-memory, .774 for the social memory, and .734 for the control memory).

Questionnaire. The questions answered for all memories concerning memory characteristics are presented in Table 1. Questions $1-13,18$, and 20 addressed the amount and type of subjective reexperiencing and the belief associated with the memory. Questions 14-17 addressed different kinds of rehearsal and the age of the memory. Question 19 addressed the consequences of the remembered event. With the exception of Question 13 concerning the specificity of the memory and Question 17 about the age of the memory, all questions were rated on 7-point scales. The response time and the characteristics probed by the questions in Table 1 are theoretically derived and basic variables in autobiographical memory research (Brewer, 1996; Conway \& Pleydell-Pearce, 2000; Rubin, 2006; Rubin \& Schulkind, 1997; Rubin \& Siegler, 2004; Tulving, 2002).

On the last page of the questionnaire, participants filled in the seven-item version of the centrality of event scale (CES; Berntsen $\&$ Rubin, 2006). This scale addresses the centrality of the remembered event to personal identity, the extent to which the memory is used as a reference point for the attribution of meaning to other events in memory, and whether the event is considered a turning point in the person's life story. It contains seven questions that are rated on 5-point Likert scales (e.g., Item 1: I feel that this event has become part of my personal identity, 1 = totally disagree, $5=$ totally agree).

\section{Results}

We found only minor effects of memory order and gender, none of which were relevant to our key questions. Hence, the groups were collapsed in our analyses. One participant recalled no memories at all and was excluded from the analyses, leaving a total of 119 participants. Six participants did not report a directive memory, and 1 of these also did not report a social memory. The reliability for the seven items included in the CES, as measured by Cronbach's $\alpha$, was acceptable for all four memory classes (.91 for the directive memory, .90 for the self-memory, .93 for the social memory, and .90 for the control memory). Following Rubin and Schulkind (1997), initial analyses for response times were conducted with both the arithmetic and the geometric mean (i.e., the logarithm of the arithmetic mean). Since there were only minor differences, we used the arithmetic mean.

Comparisons of the directive, self-, and social memories. We first analyzed the content of the memories. Eleven memories were not described, leaving a total of 457 memories (110 directive, 115 self, 114 social, and 118 control). The distribution of the 17 content categories for the remaining memories is presented in Table 2 . All four memory classes showed a diverse content that was distributed across all content categories. At the same time, the four classes of memories showed systematic differences regarding content $\left[\chi^{2}(48)=145.43, p<.0005\right]$. The most frequent category for the directive memories was stressful events, whereas the most frequent categories for the self-, social, and control memories were school, person, 
Table 2

Percentages of Directive, Self-, Social, and Control Memories Across Content Categories

\begin{tabular}{lrrrr}
\hline \multicolumn{1}{c}{ Category* } & Directive & Self & Social & Control \\
\hline Person & 15.5 & 7.8 & 13.2 & 6.8 \\
Accidents/illnesses & 5.5 & 2.6 & 8.8 & 1.7 \\
Stressful events & 19.1 & 11.3 & 6.1 & 2.5 \\
Holiday & 2.7 & 1.7 & 9.6 & 0.8 \\
Conversations & 10.0 & 5.2 & 2.6 & 5.1 \\
Leisure/sports & 0.9 & 12.2 & 11.4 & 19.5 \\
Objects or places & 5.5 & 8.7 & 7.0 & 14.4 \\
Going out & 0.9 & 1.7 & 4.4 & 6.8 \\
Work/university & 10.9 & 3.5 & 3.5 & 1.7 \\
Romantic involvement & 0.9 & 0.9 & 0.9 & 2.5 \\
School & 15.5 & 18.3 & 6.1 & 9.3 \\
Deaths/funerals & 1.8 & 3.5 & 0.9 & 1.7 \\
Special occasions & 0.9 & 4.3 & 9.6 & 11.9 \\
Births & - & 1.7 & - & - \\
Traveling/journeys & 5.0 & 7.8 & 13.2 & 3.4 \\
War/army & - & 0.9 & 0.9 & - \\
Miscellaneous & 4.5 & 7.8 & 1.8 & 11.9 \\
Total percent & 100.0 & 100.0 & 100.0 & 100.0 \\
\hline
\end{tabular}

Note-Dashes indicate 0.00. *Derived from Schlagman et al. (2006).

traveling/journeys, and leisure/sports, respectively. Thus, consistent with the predictions, the directive memories were associated with more unpleasant content than the self- and social memories were.

We next conducted a series of repeated measures ANOVAs to compare the ratings for the four memory classes. A $\chi^{2}$ test replaced the ANOVA for the specificity question. The analyses showed consistent differences for all variables, except for perspective. Since post hoc comparisons revealed that a lot of these differences were due to the control memory being rated markedly different, we performed the same analyses on the three function memories alone. The results from the analyses on the directive, self-, and social memories, without the control memories, are presented in Table 3 together with the means and standard deviations for all four classes of memories.

As shown in Table 3, consistent with our predictions, emotional valence was one of the major variables differentiating the three function memories. The mean scores on emotional valence for the self-, social, and control memories were all positive, whereas the directive memories had a negative mean score. There were 468 memories in total. A total of $265(57 \%)$ of these memories were rated as positive (scored 1-3 on emotional valence); 63 (13\%) were rated as neutral (scored 0 on emotional valence); and $140(30 \%)$ were rated as negative (scored -3 to -1 on emotional valence), but this general pleasantness bias was not found for the directive memories. Of the directive memories, $35 \%$ were rated as positive, $12 \%$ were rated as neutral, and 53\% were rated as negative. Thus, the directive memories showed a clear negativity bias. The other three classes of memories, on the other hand, showed the standard positivity bias. The percentages rated as positive were 57, 70, and 65 for the self-, social, and control memories, respectively. The corresponding percentages rated as negative were 32,20 , and 16 for the self-, social, and control memories, respectively. We confirmed that the distribution of positive, negative, and neutral memories differed between the four memories through a 3 (valence: positive, neutral, or negative) $\times 4$ (memory: directive, self, social, or control) $\chi^{2}$ test $\left[\chi^{2}(2)=51.30, p<.0005\right]$. Post hoc $\chi^{2}$ tests confirmed that this difference was the

Table 3

Means and Standard Deviations for Characteristics of Directive (Di), Self- (Se), Social (So), and Control Memories in Study 1 and Results From a Repeated Measures ANOVA on Directive, Self-, and Social Memories

\begin{tabular}{|c|c|c|c|c|c|c|c|c|c|c|}
\hline \multirow[b]{2}{*}{ Variable } & \multicolumn{2}{|c|}{ Directive } & \multicolumn{2}{|c|}{ Self } & \multicolumn{2}{|c|}{ Social } & \multicolumn{2}{|c|}{ Control } & \multirow{2}{*}{$\frac{F}{\mathrm{Di} / \mathrm{Se} / \mathrm{So}}$} & \multirow[b]{2}{*}{$\eta_{\mathrm{p}}^{2}$} \\
\hline & $M$ & $S D$ & $M$ & $S D$ & $M$ & $S D$ & $M$ & $S D$ & & \\
\hline Response time & 42.13 & 59.91 & 29.77 & 29.66 & 24.60 & 37.42 & 12.91 & 15.95 & $6.12^{* *}$ & .052 \\
\hline Physical & 2.94 & 1.87 & 2.72 & 1.87 & 3.17 & 1.99 & 2.45 & 1.70 & 1.41 & .013 \\
\hline Mood & 3.81 & 1.79 & 4.00 & 1.90 & 4.42 & 1.77 & 3.69 & 1.84 & $5.84^{* *}$ & .050 \\
\hline Back in time & 3.53 & 1.91 & 3.73 & 1.93 & 4.03 & 2.05 & 3.57 & 2.00 & $3.15^{*}$ & .027 \\
\hline Vividness & 4.46 & 1.87 & 4.68 & 1.74 & 4.64 & 1.82 & 5.40 & 1.69 & 0.95 & .008 \\
\hline Visual & 4.77 & 1.64 & 5.02 & 1.67 & 4.75 & 1.71 & 5.50 & 1.62 & 1.64 & .014 \\
\hline Auditory & 3.34 & 2.11 & 3.53 & 1.92 & 4.01 & 2.05 & 4.59 & 1.92 & $4.43^{*}$ & .038 \\
\hline Olfactory & 2.08 & 1.48 & 2.36 & 1.78 & 3.40 & 2.02 & 3.03 & 2.08 & $22.33^{* * *}$ & .167 \\
\hline Setting & 5.64 & 1.38 & 5.74 & 1.48 & 5.46 & 1.67 & 6.12 & 1.24 & 1.78 & .016 \\
\hline Reliving & 3.79 & 1.71 & 3.92 & 1.85 & 4.03 & 1.72 & 4.35 & 1.79 & 0.98 & .009 \\
\hline Perspective & 3.36 & 2.20 & 3.38 & 2.15 & 3.04 & 2.00 & 2.88 & 2.04 & 1.13 & .010 \\
\hline Valence & -0.31 & 1.93 & 0.52 & 1.99 & 1.23 & 1.92 & 1.01 & 1.57 & $18.50^{* * *}$ & .143 \\
\hline Intensity & 4.41 & 1.68 & 4.19 & 1.75 & 4.18 & 1.86 & 3.36 & 1.76 & 0.65 & .006 \\
\hline Specificity & 0.52 & 0.50 & 0.51 & 0.50 & 0.43 & 0.50 & 0.92 & 0.28 & $2.54^{+}$ & \\
\hline Covert & 4.73 & 1.54 & 4.55 & 1.66 & 4.90 & 1.53 & 3.34 & 1.81 & 1.49 & .013 \\
\hline Overt & 3.73 & 1.80 & 3.66 & 1.93 & 5.13 & 1.44 & 3.19 & 1.83 & $30.80^{* * *}$ & .217 \\
\hline Involuntary & 4.14 & 1.68 & 4.02 & 1.67 & 4.20 & 1.61 & 2.91 & 1.72 & 0.31 & .003 \\
\hline Age of memory & 4.13 & 4.06 & 5.06 & 4.81 & 4.06 & 4.40 & 0.01 & 0.09 & 2.12 & .019 \\
\hline Belief & 5.75 & 1.42 & 5.96 & 1.39 & 5.42 & 1.62 & 6.28 & 1.16 & $6.15^{* *}$ & .054 \\
\hline Consequences & 4.70 & 1.63 & 4.29 & 1.92 & 3.80 & 1.97 & 2.03 & 1.42 & $7.10^{* *}$ & .061 \\
\hline Coherence & 3.42 & 1.73 & 3.74 & 1.81 & 3.38 & 1.89 & 4.45 & 1.88 & 2.50 & .022 \\
\hline CES score & 3.04 & 1.04 & 3.00 & 1.05 & 2.59 & 1.11 & 1.46 & 0.65 & $6.79^{* *}$ & .059 \\
\hline
\end{tabular}


result of the directive memory being unpleasantly biased, consistent with our predictions and the content analysis.

As also shown in Table 3, most other differences were found between the social memory and the other two memories, with olfactory imagery and overt rehearsal being the major differentiating variables. In contrast, the means for the directive and self-memories were quite similar for most variables, consistent with the assumption of some overlap between these two functions. Furthermore, the social memories were generally rated higher on phenomenological measures (e.g., mood impact, mentally traveling back in time, auditory imagery, and reliving) than the self- and directive memories, whereas the directive and self-memories were rated higher on event measures, such as consequences and the centrality of the event to the person's identity and life story. Finally, it is noticeable that although participants were carefully instructed to generate memories of specific events, only half of the three function memories were rated as specific, suggesting that generalized memories also serve important functions. A $\chi^{2}$ test showed no differences in the frequency of specific versus generalized events among the three classes of memories (see Table 3 ).

The results from the post hoc comparisons between the three function memories alone (see Table 3) gave overall support to our hypotheses. As predicted, social memories and self-memories were rated more positive than directive memories $(p<.005)$, but social memories were also rated more positive than self-memories $(p<.01)$. As also predicted, directive memories had longer response times than did self- and social memories $(p<.05)$, and directive and self-memories were both rated higher on consequences and the centrality of event to the person's identity and life story than social memories $(p<.05)$. Contrary to our expectations, there were no differences between the directive and self-memories on the total CES score or consequences, although there was a trend for consequences $(p<.08)$ in the predicted direction.

In order to examine the interplay between memory and rehearsal, we conducted a 3 (memory: directive, self, or social) $\times 3$ (rehearsal: overt, covert, or involuntary) repeated measures ANOVA. There were significant main effects for both memory $\left[F(2,222)=9.14, p<.0005, \eta_{\mathrm{p}}^{2}=.08\right]$ and rehearsal $\left[F(2,222)=27.39, p<.0005, \eta_{\mathrm{p}}^{2}=.20\right]$, and a significant interaction $\left[F(4,444)=18.13, p<.0005, \eta_{\mathrm{p}}^{2}=\right.$ $.14]$. As shown by Figure 1, the interaction was largely due to the social memory's being rated considerably higher on overt rehearsal than the directive and self-memories.

\section{Discussion}

Overall, the findings supported the predictions that the directive, self-, and social memories differ systematically on emotional content and basic memory variables. The self- and social memories were mostly positive, whereas the directive memories were mostly negative. The directive memories had longer response times than the selfmemories and the social memories did, supporting the idea that these memories are less accessible for voluntary recall, because automatic retrieval may be their favored mode of activation (Berntsen, 2009b; Pillemer, 2003). The

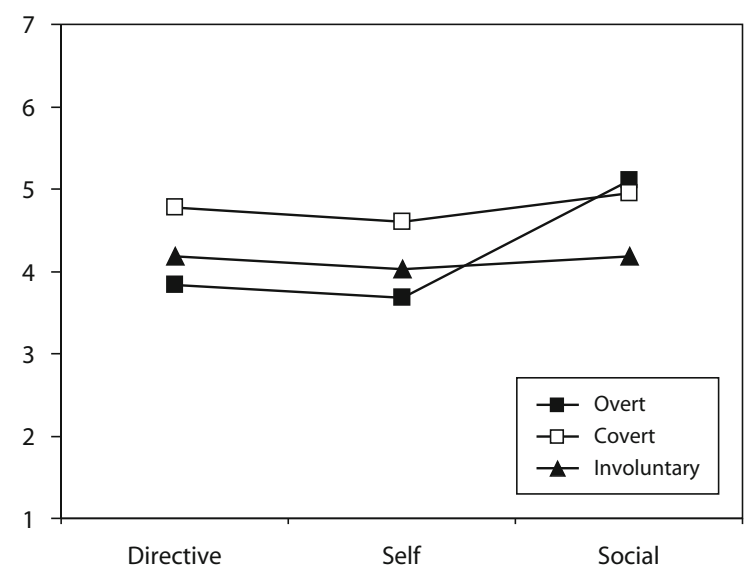

Figure 1. Mean ratings of overt, covert, and involuntary rehearsal for the directive, self-, and social memories in Study 1.

directive memories were more consequential, and the selfmemories were more central to the person's identity and life story, than the social memories. Contrary to our expectations, the self- and directive memories were equally consequential and central to the person's identity and life story. There seems to be some overlap between these two functions, as was also suggested by the literature on the directive function (e.g., Pillemer, 1992, 2003), although the directive memories were markedly more negative.

The predicted relation between the three functions and rehearsal was only partly confirmed. Social memories were more talked about than self- and directive memories, thus confirming our expectations regarding overt rehearsal. However, contrary to our predictions, directive and self-memories did not differ on covert and involuntary rehearsal. One problem with the interpretation of these findings is that the question addressing covert rehearsal (no. 14, in Table 1) was formulated in a way that might have included both deliberate and involuntary covert rehearsal, thus hiding any dominant effect of involuntary rehearsal for the directive memory. In Study 2, which addressed this differentiation, we made a clearer distinction between voluntary and involuntary rehearsal.

The distribution of emotional valence for the directive memories differs from that of the other three classes of memories in that the participants recalled substantially more negative memories. Thus, the emotional content of the directive memory differs markedly from what would be expected from the general pleasantness bias in autobiographical memory (Walker et al., 2003), but agrees with suggestions about the role of negative memories in problem solving (Levine \& Bluck, 2004). Hence, it may be adaptive to remember the negative consequences associated with directive memories without being flooded by the unpleasant reliving associated with such memories, as also suggested in the literature on hypothesized functions of positive and negative memories (e.g., Bohn \& Berntsen, 2007, for a review). This explanation is further supported by the long response time, high ratings on consequences, low ratings on mood impact, mentally traveling back in time, and au- 
ditory and olfactory imagery for the directive memories when compared with the self- and the social memories.

In conclusion, the directive and self-memories were more central to the person's identity and life story than the social memories, but the directive memories were less accessible than self-memories and more frequently referred to negative events. The self-memories, on the other hand, were more positive, although not as positive as the social memories, and they tended to fall midway between the directive and social memories regarding accessibility and phenomenology. The directive and self-memories were both more consequential and central to the person's identity and life story than the social memories. Finally, emotional valence was the only variable that differentiated all three classes of function memories significantly from each other. The relationship between the three functions and emotional valence was further addressed in Study 2.

\section{STUDY 2}

Whereas Study 1 addressed the response times and the characteristics of memories triggered by function cues, memories in Study 2 were triggered by descriptions of memory content, and the directive, self-, and social functions were treated as dimensions rated for each memory. In order to further study the relationship between the three functions and emotional valence found in Study 1, we examined the participants' most positive and negative memories. In addition, we examined the participants' most frequent involuntary and most vivid flashbulb memories, since both classes of memories have been considered in relation to specific functions. As already mentioned, involuntary retrieval may be the favored mode of activation for directive memories (see, e.g., Berntsen, 2009b; Pillemer, 2003), which can be seen to agree with the longer response times (i.e., lower accessibility for strategic or voluntary recall) for the directive memories in Study 1. Following this view, the directive function may be especially pronounced for involuntary memories. Flashbulb memories (i.e., remembering one's personal circumstances when receiving the news of an important public event; Brown \& Kulik, 1977) have been associated with important social functions (e.g., Neisser, 1982b; see Winograd \& Neisser, 1992, for a review), among other things, because people tend to share these memories with others due to high media exposure of the event.

In Study 2, we thus examined the participants' most positive and most negative memories, their most frequent involuntary and most vivid flashbulb memories, and a control memory on response time, function, memory characteristics, and the centrality of event to the person's identity and life story. We also explored the overall interplay between memory class and function. On the basis of the results from Study 1, we predicted that positive memories would be rated higher on self- and social function than negative memories, whereas negative memories would be rated higher on directive function. Furthermore, on the basis of previous work (e.g., Bohn \& Berntsen, 2007; Levine \& Pizarro, 2004), we predicted that positive memories would be easier to access (i.e., have shorter response times and higher ease of recall) and rated higher on phenomenological measures - such as sensory imagery, vividness, and mentally traveling back in time and reliving - than negative memories. Finally, because we treated the three functions as dimensions, we were able to examine through correlation analyses whether the three functions related differently to other characteristics of autobiographical memory. In this regard, on the basis of the results from Study 1, we expected that the centrality of the event to the person's identity and life story and consequences would be positively related to the directive and self-functions, whereas we expected overt rehearsal to be positively related to the social function. We expected to find this pattern across all five memories.

\section{Method}

Participants. A total of 136 (115 women and 21 men, mean age 25.71 years, $S D=4.95$, range $20-43$ years) psychology undergraduates participated as part of a psychology research methods course. As in Study 1, all participants were informed that their responses were anonymous, and it was clearly stated that they were free to withdraw at any point during the procedure.

Procedure. The participants followed a procedure similar to that in Study 1 for five classes of memories, in the following or reversed order: involuntary, positive, control, negative, and flashbulb. The participants were first offered a definition and an example of the memories. The cue for each memory was hidden under a label on the first page of the memory questionnaire. The participants were instructed to remove the label and read the cue immediately after they had started the stopwatches. The procedure then continued as in Study 1.

Cues. The cue for the most positive memory was Your most positive memory. The cue for the most negative memory was Your most negative memory. The cue for an involuntary memory was Your most frequently experienced involuntary memory. The cue for the flashbulb memory was Your most vivid flashbulb memory. Finally, the cue for the control memory was equivalent to the control cue in Study 1: A random event from the last week. The memory cues were formulated as extremes in order to maximize possible differences among the memories. The order of the cues was randomized across two groups, with 70 and 66 participants in each group.

Questionnaire. The memory questionnaire from Study 1 (see Table 1) was changed in order to measure memory functions as rating-scale questions, to differentiate more precisely between voluntary and involuntary rehearsal, and to obtain a subjective measure for how easily the memories were accessed. The two questions about specificity and belief were left out (Questions 13 and 18 in Table 1). Questions 1-3 addressing memory functions were added. They were developed from a conversion of the function cues used in Study 1 and had been validated against the corresponding functions in a reliable survey measure used in previous work (see Alea \& Bluck, 2007a; Bluck et al., 2005). The validation was done because we wanted to ensure that the single rating-scale questions would capture the theoretical breadth of the three functions. Details from the validation study can be obtained from the first author. Question 1 addressed the directive function; Question 2 addressed the self-function; and Question 3 addressed the social function. The questions were: (1) I think of this memory in order to handle present or future situations; (2) This memory tells me something about my identity; (3) I have often shared this memory with other people. The three questions were rated on 7 -point scales $(1=$ not at all, $7=$ to a very high degree). We added a fourth question addressing social identity: This memory gives me a sense of where I belong, and whom I identify with socially and culturally. This question was added because neither the social function question nor the self-function question captured the relevance of the memory for the person's social - as opposed to personal-identity (Berntsen, 2009a). These four questions were 
Table 4

Means and Standard Deviations for the Most Positive and Most Negative Memory in Study 2 and Results From a $t$ Test

\begin{tabular}{|c|c|c|c|c|c|c|}
\hline \multirow[b]{2}{*}{ Variable } & \multicolumn{2}{|c|}{ Positive } & \multicolumn{2}{|c|}{ Negative } & \multirow[b]{2}{*}{$t$} & \multirow[b]{2}{*}{$\eta_{\mathrm{p}}^{2}$} \\
\hline & $M$ & $S D$ & $M$ & $S D$ & & \\
\hline Response time & 32.07 & 38.87 & 23.14 & 43.88 & $2.33^{*}$ & .039 \\
\hline Directive & 3.26 & 1.80 & 3.62 & 1.90 & $-2.05^{*}$ & .030 \\
\hline Self & 5.19 & 1.69 & 4.90 & 1.71 & $1.71\left(^{*}\right)$ & .021 \\
\hline Social & 4.74 & 2.00 & 4.22 & 1.84 & $2.66^{* *}$ & .048 \\
\hline Social identity & 4.99 & 1.87 & 3.50 & 1.92 & $7.66^{* * *}$ & .303 \\
\hline Physical & 4.43 & 2.02 & 4.44 & 1.98 & -0.04 & .001 \\
\hline Mood & 5.37 & 1.64 & 4.82 & 1.83 & $3.55^{* *}$ & .085 \\
\hline Back in time & 4.89 & 1.72 & 4.32 & 1.80 & $3.66^{* *}$ & .073 \\
\hline Vividness & 5.42 & 1.45 & 5.17 & 1.59 & 1.48 & .016 \\
\hline Visual & 5.61 & 1.31 & 5.37 & 1.62 & 1.15 & .017 \\
\hline Auditory & 3.33 & 1.91 & 3.38 & 1.90 & -0.28 & .001 \\
\hline Olfactory & 3.11 & 1.94 & 2.47 & 1.74 & $3.35^{* *}$ & .077 \\
\hline Setting & 6.06 & 1.18 & 5.99 & 1.23 & 0.57 & .002 \\
\hline Reliving & 4.77 & 1.55 & 4.27 & 1.70 & $3.35^{* *}$ & .077 \\
\hline Perspective & 2.93 & 2.05 & 2.89 & 2.00 & 0.19 & .001 \\
\hline Valence & 2.53 & 0.63 & -2.24 & 0.87 & $50.12^{* * *}$ & .949 \\
\hline Intensity & 5.52 & 1.26 & 5.12 & 1.64 & $2.61^{*}$ & .048 \\
\hline Overt & 4.76 & 1.78 & 4.35 & 1.75 & $2.26^{*}$ & .036 \\
\hline Voluntary & 5.08 & 1.56 & 3.58 & 1.87 & $8.18^{* * *}$ & .331 \\
\hline Involuntary & 4.31 & 1.63 & 4.71 & 1.54 & $-2.43^{*}$ & .042 \\
\hline Age of memory & 5.03 & 5.38 & 7.47 & 6.49 & $-3.80^{* * * *}$ & .096 \\
\hline Consequences & 5.03 & 1.97 & 5.27 & 1.54 & -1.21 & .011 \\
\hline Coherence & 4.63 & 1.67 & 4.35 & 1.76 & $1.72\left(^{*}\right)$ & .021 \\
\hline Ease of access & 5.11 & 1.72 & 5.57 & 1.47 & $-2.79^{* *}$ & .054 \\
\hline CES score & 3.51 & 1.06 & 3.56 & 0.91 & -0.50 & .002 \\
\hline
\end{tabular}

given first. The rest of the questions followed in the same order as in Study 1. Question 14 in Study 2 (see Table 1) was changed into: Since it happened, I have deliberately sought back to the event in my mind $(1=$ almost never, $7=$ extremely often $)$. The following question was added last to measure the person's own judgment of the accessibility of each memory and thereby supplement the response times with a subjective measure of accessibility: This memory was easy to recall $(1=$ not at all, $7=$ to a very high degree $)$. Finally, the participants filled in the seven-item CES for each memory.

\section{Results}

We found only minor effects of memory order and gender, none of which were relevant for our key questions. Hence, as in Study 1, the groups were collapsed in our analyses. Six participants did not report an involuntary memory, and 3 did not report a control memory. The reliability for the seven items included in the CES (as measured by Cronbach's $\alpha$ ) was acceptable for all memories (.90 for the positive memory, .86 for the negative memory, .93 for the involuntary memory, .90 for the control memory, and .89 for the flashbulb memory). As in Study 1, since initial analyses for response times showed only minor differences between the arithmetic and geometric means, we used the simpler arithmetic mean throughout the study.

Comparisons of the most positive and most negative memories. The results of paired-sample $t$ tests between the most positive and the most negative memories are presented in Table 4, together with the means and standard deviations. As predicted, the participants' most negative memories had more directive function than did their most positive memories, and their most positive memories had more self- and social function than did their most negative memories, although there was only a trend for the self-function in the expected direction. Hence, the results from Study 1 concerning the relationship between function and emotional valence were replicated. As also predicted, positive memories were rated higher than negative memories on most of the phenomenological variables, consistent with earlier studies and the results from Study 1. Contrary to our predictions about accessibility, positive memories had longer response times than did negative memories, and they were rated as being harder to recall. Finally, positive memories were rated higher on social identity than negative memories.

The results on voluntary and involuntary rehearsal suggested an interaction between positive versus negative memory and covert rehearsal. We therefore conducted a 2 (memory: positive vs. negative) $\times 2$ (rehearsal: voluntary vs. involuntary) repeated measures ANOVA, which showed a main effect for memory $[F(1,135)=15.12, p<.0005$, $\left.\eta_{\mathrm{p}}^{2}=.10\right]$ and confirmed the interaction between memory and rehearsal $\left[F(1,135)=83.68, p<.0005, \eta_{\mathrm{p}}^{2}=.38\right]$. As shown in Table 4, this interaction was largely due to the positive memories being rated considerably higher than the negative memories on voluntary rehearsal $(p<.0005)$, whereas there was a smaller, but still significant, effect in the opposite direction for involuntary rehearsal $(p<.05)$.

Comparison of function across all five memories. In order to examine the overall interplay between function and memory, we conducted a 5 (memory: positive, 


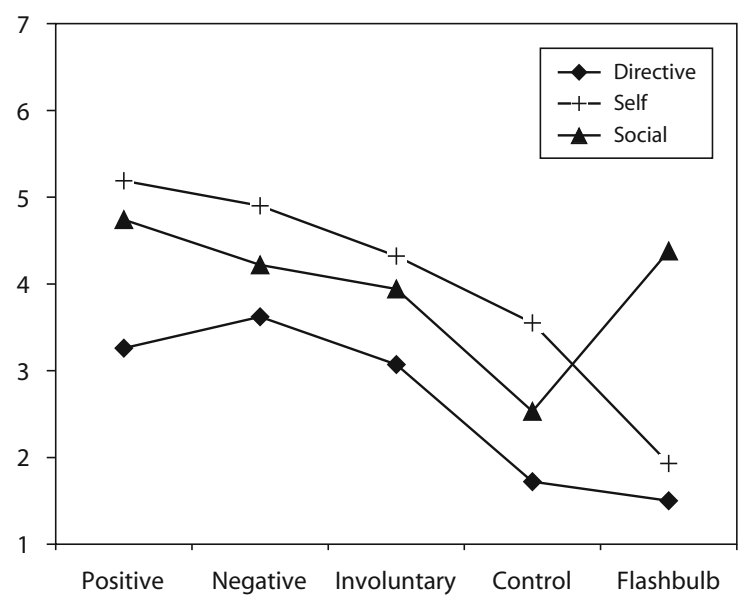

Figure 2. Mean ratings of the directive, self-, and social functions for the positive, negative, involuntary, flashbulb, and control memories in Study 2.

negative, involuntary, control, or flashbulb) $\times 3$ (function: directive, self, or social) repeated measures ANOVA. There were significant main effects for both memory $\left[F(4,504)=74.48, p<.0005, \eta_{\mathrm{p}}^{2}=.37\right]$ and function $\left[F(2,252)=106.60, p<.0005, \eta_{\mathrm{p}}^{2}=.46\right]$, reflecting that the directive function was rated lowest for all memories, and there was a significant interaction $[F(8,1008)=37.75$, $\left.p<.0005, \eta_{\mathrm{p}}^{2}=.23\right]$, confirming that different memories serve different functions. As shown in Figure 2, consistent with our predictions, the interaction seemed to be largely due to the flashbulb memory's being rated considerably higher on the social function than the other memories. In order to examine this possibility more carefully, we left out the flashbulb memory in a 4 (memory: positive, negative, involuntary, or control) $\times 3$ (function: directive, self, or social) repeated measures ANOVA. Again, there were significant main effects for both memory $[F(3,378)=60.13$, $\left.p<.0005, \eta_{\mathrm{p}}^{2}=.32\right]$ and function $[F(2,252)=77.80$, $\left.p<.0005, \eta_{\mathrm{p}}^{2}=.38\right]$, as well as a significant interaction $\left[F(6,756)=5.23, p<.0005, \eta_{\mathrm{p}}^{2}=.04\right]$, suggesting that the remaining classes of memories in the analysis varied on the extent to which they involved the three functions. The predicted relation between involuntary memories and the directive function was not confirmed (see Figure 2).

Relations between function and other memory characteristics across all five memory classes. We first examined the correlations between the three functions and the rest of the memory variables within each memory. The results are presented in Table 5, with the significance level adjusted for multiple correlations within each function (Bonferroni method). Across all five memories, and consistent with Study 1 and the predictions, the directive and self-functions correlated positively with consequences and the CES (Berntsen \& Rubin, 2006), whereas the social function correlated positively with overt rehearsal. In addition, across all five memories, the directive and social function correlated positively with voluntary rehearsal, whereas the self-function correlated positively with social identity.
In order to further examine these relations, we conducted a set of multiple regression analyses with the three functions as dependent variables, and the significantly correlated memory characteristics as independent variables (see Table 5). Across all five memories, the results showed that the centrality of event for the person's identity and life story was a predictor for the directive function ( $R^{2}$ from .29 to $.44 ; \beta$ from .23, $p<.05$, to $.69, p<.0005$; $N$ from 128 to 135$)$ and self-function $\left(R^{2}\right.$ from .41 to .55 ; $\beta$ from .24, $p<.05$, to $.52, p<.0005 ; N$ from 128 to $135)$, whereas social identity was a predictor for the selffunction ( $\beta$ from .24, $p<.01$, to $.52, p<.0005$ ). Overt rehearsal was the only predictor for the social function across all five memories ( $R^{2}$ from .69 to $.80 ; \beta$ from .65 , $p<.0005$, to $.88, p<.0005 ; N$ from 128 to 135 ). None of the other independent variables showed significant effects across all five memories.

The positive relation between consequences and the directive and self-functions shown in Table 5 was almost eliminated in these analyses. However, this was most likely due to a high correlation between consequences and the centrality of event to the person's identity and life story for all five memories (.73-.82). The high $\beta$ values for overt rehearsal as a predictor for the social function could be explained by a large conceptual overlap between these two variables. We therefore ran a new set of multiple regression analyses - one with the directive and self-function functions as dependent variables, but leaving out the centrality of event to the person's identity and life story as one of the independent variables, and one with the social function as dependent variable, but leaving out overt rehearsal as one of the independent variables. Across all five memories, social identity predicted the self-function $\left(R^{2}\right.$ from .38 to $.50 ; \beta$ from $.31, p<.0005$, to $.53, p<.0005$; $N$ from 128 to 135 ), whereas voluntary rehearsal predicted the social function ( $R^{2}$ from .25 to $.74 ; \beta$ from $.23, p<$ .05 , to $.50, p<.0005 ; N$ from 129 to 135 ). Consequences predicted the directive function for the involuntary $\left(R^{2}=\right.$ $.36 ; \beta=.37, p<.0005 ; N=129)$, flashbulb $\left(R^{2}=.40\right.$; $\beta=.24, p<.01 ; N=135)$, and control $\left(R^{2}=.27 ; \beta=\right.$ $.34, p<.01 ; N=132)$ memories, whereas it predicted the self-function for the negative $\left(R^{2}=.39 ; \beta=.41, p<\right.$ $.0005 ; N=129)$ and involuntary $\left(R^{2}=.50 ; \beta=.33, p<\right.$ $.0005 ; N=129$ ) memories. None of the other independent variables showed significant effects across all five memories.

\section{Discussion}

The results gave overall support to the hypotheses regarding differences between the participants' most positive and negative memories. The hypotheses were confirmed with respect to the directive, self-, and social functions; olfactory imagery; and mentally traveling back in time and reliving, although the results for self-function were only a trend. We found no significant differences for the visual imagery and vividness of the positive versus negative memories, but the results were in the expected directions. In other words, in comparison with negative memories, positive memories had higher levels of self- and social function and higher ratings of phenomenological charac- 


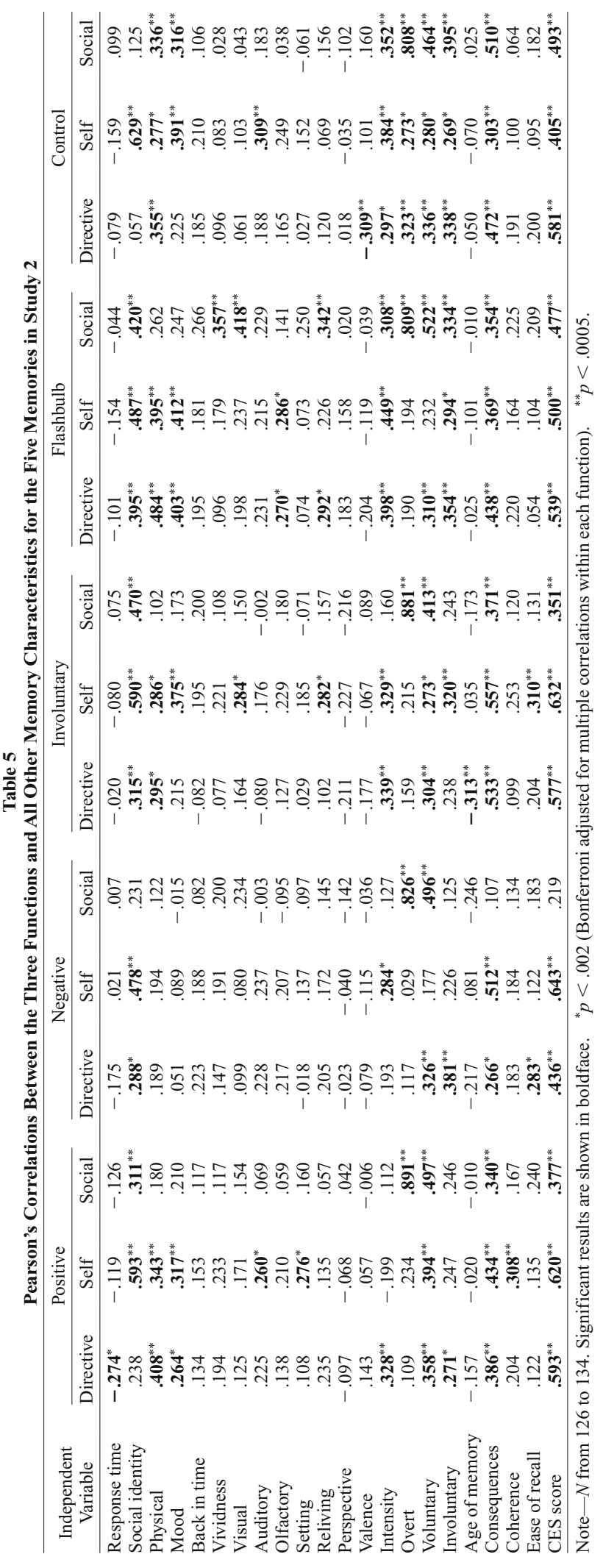


teristics in general, whereas negative memories had higher levels of directive function. These results replicate and extend those from Study 1, and agree with our predictions about a relationship between memory function and emotional valence. Unexpectedly, we found that positive memories had longer response times and were rated as harder to recall than their negative counterparts. A possible explanation for these results is that the participants in the present study were instructed to recall their most positive and most negative memory, whereas the participants in earlier studies (e.g., Andersson et al., 2006; Collins et al., 2007; Lishman, 1974) were instructed to recall less extreme memories. Because of the pleasantness bias, there would be more highly positive than highly negative memories to choose from, hence prolonging the response times for the most positive memories and making them seem harder to recall.

We found an interaction between memory and rehearsal, which showed that the positive memories were more voluntarily rehearsed than the negative memories, whereas the negative memories were more involuntarily rehearsed. Slightly more involuntary rehearsal for negative than for positive memories has been found in previous work (Rubin, Boals, \& Berntsen, 2008). In the present study, the effect was largely driven by the positive memories' being rated much higher than the negative memories on voluntary rehearsal (see Table 4), and was most likely due to our new and more specific formulation of the question for voluntary rehearsal that addressed deliberately thinking back on the event.

In addition to the negative memories having higher ratings on the directive function than those of positive memories, there was an overall main effect for function, reflecting that the directive function was less pronounced than the other two functions across all memory types. We also found an interaction between memory type and function, partly reflecting that the flashbulb memories had markedly more social function than directive and self-function, when compared with the other four memories. This result is consistent with the idea that flashbulb memories are often shared in conversation. The interaction was markedly reduced, but still significant, when the analysis was conducted without the flashbulb memories. This result confirms that the four remaining classes of memories also varied on the extent to which they involved each of the three functions. Contrary to the predictions, involuntary memories were not clearly associated with the directive function, but seemed to follow the same pattern as the positive, negative, and control memories, with the self-function as the most dominant function, followed by the social and directive functions. However, it is possible that our failure to find an association between involuntary memory and directive function was due to the retrospective sampling of involuntary memories in the present study. Future studies should examine the functions of involuntary memories in diary studies with online sampling.

Correlation and multiple regression analyses confirmed that consequences and the centrality of event to the person's identity and life story were related to the directive and self-functions across all five memories, but consequences was a less robust predictor for these two functions in that it was not found for all five memories. These results are largely consistent with our analyses in Study 1 of differences and overlaps between these two functions. As was also expected, overt rehearsal was a predictor for the social function across all five memories. Furthermore, voluntary rehearsal was the only predictor for the social function for all five memories when overt rehearsal was taken out of the regression equation, suggesting that rehearsal in general is strongly associated with the social function. This result again replicated and extended the differences and overlaps between the three functions found in Study 1. Finally, social identity was a predictor for the self-function across all five memories, suggesting that this variable has more in common with the self- than with the social function.

\section{GENERAL DISCUSSION}

References to hypothesized functions of certain classes or types of memories are frequent and span more than three decades of autobiographical memory research (see, e.g., Brown \& Kulik, 1977; Neisser, 1982b; Pillemer, 2003; Talarico et al., 2009), but very little research has been conducted in order to examine the assumption that different memory classes serve different functions. In the present article, we have presented the first series of studies that systematically examine and compare the functions of individual memories, and we have introduced a new method for this purpose. First, across the two studies, we have provided clear evidence showing that different classes of memories are associated with different functions. Second, using the tripartite model of memory function (e.g., Bluck et al., 2005) as a theoretical framework, we have demonstrated that directive, self-, and social functions can be used as discrete memory cues and also serve as ratingscale dimensions for specific instances of autobiographical memories. In the latter case, each function is viewed as a matter of degree rather than as a discrete categorization, with the implication that any memory may serve all three functions to various extents, and that memories may differ from one another with respect to the degree to which each of the three functions is represented. Third, we have found systematic relations between the three functions and emotional valence in both studies, treating functions both as discrete memory cues and as dimensions to be rated within each memory. We have thereby provided a thorough cross-examination of the specific hypothesis that positive memories are associated with more self- and social function than negative memories, whereas negative memories are associated with more directive function.

In Study 1, we found that the three function memories differed systematically on basic memory characteristics, consistent with our predictions. Directive memories were dominated by negative emotion and unpleasant content, whereas self- and social memories were dominated by positive emotion and more pleasant content. Directive memories had longer response times than did self- and social memories. Directive and self-memories were rated as more central to the person's identity and life story than 
social memories, which is consistent with speculations on the self-referential aspects of the directive function (see, e.g., Pillemer, 2003). Social memories were more talked about than were directive and self-memories, whereas there were no differences in rehearsal between the directive and self-memories. Thus, we confirmed our predictions about the interplay between the three functions and emotional valence, and we showed that the tripartite model can be applied to, and meaningfully differentiates, individual memories.

One limitation of Study 1 was that the memories were elicited in response to complex descriptions of functions. One might argue that such memories are a rare and artificial phenomenon with little relevance outside the laboratory. In Study 2, we therefore used another research strategy in that we converted the function descriptions into rating-scale questions and examined the ratings of the participant's most positive and negative memories, as well as their most frequent involuntary and most vivid flashbulb memories. Contrary to the three function cues, the real-world relevance of these memory cues has been documented in numerous studies (e.g., Berntsen \& Rubin, 2002; Berntsen \& Thomsen, 2005; Collins et al., 2007; D'Argembeau, Comblain, \& Van der Linden, 2003; D'Argembeau \& Van der Linden, 2004).

Consistent with those of Study 1, the findings from Study 2 showed that positive memories had more selfand social function than negative memories did, whereas negative memories had more directive function. Furthermore, findings from Study 2 also replicated the relations between function and other memory characteristics found in Study 1. Consequences, and the centrality of event to the person's identity and life story, were positively related to the directive and self-functions, whereas overt rehearsal was positively related to the social function. Finally, consistent with previous research (e.g., Bohn \& Berntsen, 2007; D'Argembeau \& Van der Linden, 2004), positive memories were rated higher than negative memories on most phenomenological variables. However, contrary to the results of earlier studies (e.g., Andersson et al., 2006; Collins et al., 2007; Lishman, 1974) and expectations generated from the pleasantness bias (Walker et al., 2003), negative memories had shorter response times and were rated as easier to recall than positive memories. As argued earlier, this might have been due to the instruction to record the most positive and most negative memories in the present study, because of more potential candidates in the positive memory class.

How well did we answer our overall question as to whether different memories serve different functions? The inclusion of involuntary and flashbulb memories in Study 2 showed that factors other than emotional valence influence functional differences between autobiographical memories. In the present article, we have devoted most of our attention to the relationship between the three functions and emotional valence, but function may also vary across discrete emotions. Accordingly, the next logical step for future studies would be to examine the functions of memories elicited in response to discrete emotions var- ied on valence and intensity (see, e.g., Talarico, LaBar, \& Rubin, 2004).

Another important issue for future research concerns the directive function. In agreement with speculations and research suggesting that memory directives are difficult to access through goal-directed and strategic retrieval (Hyman \& Faries, 1992; Pillemer, 2003), we have found longer response times for the directive memories than for self- or social memories, as well as lower ratings for the directive function than for the self- and social functions across five different classes of memories. However, we did not find the predicted relation between the directive function and involuntary recall. Future studies should pursue this finding in diary studies with online recording of involuntary and voluntary memories in order to examine whether involuntary memories serve more directive functions than voluntary memories, as might be expected from an evolutionary perspective (see, e.g., Pillemer, 2003).

\section{Broader Implications}

The present findings show that individual memoriesand positive and negative memories in particular - are different according to the tripartite model of memory function. However, importantly, the results also show that the general pleasantness bias in autobiographical memory does not apply to all memories, in that memories with directive functions are dominated by negative emotion. Given the pervasiveness of the pleasantness bias (Walker et al., 2003), this is an important novel finding that adds to our knowledge of the pleasantness bias as well as to our knowledge of memory functions. In a broader perspective, it may suggest a solution to the enigma concerning evolutionary functions of positive and negative memories. The enigma is how we can learn from past mistakes if we constantly tone down aspects associated with negative memories in order to maintain a positive illusion of the current self and to facilitate social bonding (see, e.g., Fredrickson, 2001; Ross \& Wilson, 2002, 2003; Taylor \& Brown, 1988). The answer may be that although we distance ourselves from the painful emotional reliving of negative memories, we still remember just enough of the details necessary to solve problems and prevent future mistakes (e.g., Bohn \& Berntsen, 2007; Levine \& Bluck, 2004; Levine \& Pizarro, 2004). This idea agrees with results of studies showing a dominance of central details in negative memories, and peripheral details in positive memories (Berntsen, 2002; Talarico et al., 2009). In this interpretation, memory for central details, at the expense of peripheral details, enables the negative recollection to serve directive functions. This fits with the general assumption that one important role of autobiographical memory is to maintain a positive self-image. In this regard, the directive function may be seen as an evolutionarily more basic function that keeps track of reality when demanded by survival pressures (e.g., Nairne \& Pandeirada, 2008; Nairne, Thompson, \& Pandeirada, 2007).

The findings also have implications for theories on the relation between traumatic memories and the development of PTSD. Some theories assume that trauma memories 
follow special mechanisms leading them to be dissociated or repressed from autobiographical memory, and that this disintegration is responsible for the development of PTSD (see, e.g., Dalgleish, 2004; Horowitz, 2001; JanoffBulman, 1992; van der Kolk \& Fisler, 1995). In contrast, other researchers have argued that trauma memories invoke no special mechanisms such as repression, but that they follow the same mechanisms as other emotionally intense memories do. In other words, trauma memories can be explained in terms of normal memory mechanisms applied to extreme conditions (Rubin, Berntsen, \& Bohni, 2008). Our findings support the latter view. Although the phenomenological and emotional contents of highly negative memories are clearly reduced as compared with those of highly positive memories, there is no evidence in favor of repression. Nonetheless, PTSD symptoms may affect the person's ability to use his or her memories in an adaptive way. An important task for future research, therefore, might be to compare the functions of trauma memories in populations with and without PTSD.

\section{Conclusions}

We have presented the first series of studies that systematically compare the functions of specific memories, and in particular the functions associated with emotionally positive and negative memories. We have shown that memory function varies in predictable ways according to memory content, and that the relationship between emotional valence and the function of individual autobiographical memories is consistent with hypothesized evolutionary functions of positive and negative memories. Positive memories keep up the good spirits of life, whereas negative memories keep it real.

\section{AUTHOR NOTE}

Thanks to Annette Bohn, Kim Berg Johannessen, Amanda Miles, and Dorthe Kirkegaard Thomsen for comments on the manuscript. Thanks to Tua Preuss and Line Glibstrup Sørensen for their assistance, and to the Danish Research Council for the Humanities for funding. Address correspondence to A. S. Rasmussen, Department of Psychology, Aarhus University, Jens Chr. Skous Vej 4, 8000 Aarhus C., Denmark (e-mail: annesr@psy.au.dk).

\section{REFERENCES}

Alea, N., \& BlucK, S. (2003). Why are you telling me that? A conceptual model of the social function of autobiographical memory. Memory, 11, 165-178. doi:10.1080/741938207

ALEA, N., \& BluCK, S. (2007a, July). Autobiographical memory in everyday life: What the hell is it for? Paper presented at the 7th biennial meeting of the Society for Applied Research in Memory and Cognition (SARMAC), Lewiston, ME.

Alea, N., \& Bluck, S. (2007b). I'll keep you in mind: The intimacy function of autobiographical memory. Applied Cognitive Psychology, 21, 1091-1111. doi:10.1002/acp.1316

Andersson, G., Boethius, S. B., Svirsky, L., \& Carlberg, G. (2006). Memories of significant life episodes in childhood psychotherapy: An autobiographical memory approach. Psychology \& Psychotherapy: Theory, Research \& Practice, 79, 229-236. doi:10.1348/147608305X53198

BADDELEY, A. (1988). But what the hell is it for? In M. M. Gruneberg, P. E. Morris, \& R. N. Sykes (Eds.), Practical aspects of memory: Current research and issues (Vol. 1, pp. 3-18). Chichester, U.K.: Wiley.

Baumeister, R. F., Bratslavsky, E., Finkenauer, C., \& Vohs, K. D. (2001). Bad is stronger than good. Review of General Psychology, 5, 323-370. doi:10.1037/1089-2680.5.4.323
BERNTSEN, D. (2002). Tunnel memories for autobiographical events: Central details are remembered more frequently from shocking than from happy experiences. Memory \& Cognition, 30, 1010-1020.

Berntsen, D. (2009a). Flashbulb memory and social identity. In O. Luminet \& A. Curci (Eds.), Flashbulb memories: New issues and new perspectives (pp. 187-205). Hove, U.K.: Psychology Press.

BERNTSEN, D. (2009b). Involuntary autobiographical memories: An introduction to the unbidden past. Cambridge: Cambridge University Press.

Berntsen, D., \& Rubin, D. C. (2002). Emotionally charged autobiographical memories across the life span: The recall of happy, sad, traumatic, and involuntary memories. Psychology \& Aging, 17, 636-652. doi: $10.1037 / 0882-7974.17 .4 .636$

Berntsen, D., \& Rubin, D. C. (2006). The centrality of event scale: A measure of integrating a trauma into one's identity and its relation to post-traumatic stress disorder symptoms. Behaviour Research \& Therapy, 44, 219-231.

Berntsen, D., \& Rubin, D. C. (2007). When a trauma becomes a key to identity: Enhanced integration of trauma memories predicts posttraumatic stress disorder symptoms. Applied Cognitive Psychology, 21, 417-431. doi:10.1002/acp.1290

Berntsen, D., \& Thomsen, D. K. (2005). Personal memories for remote historical events: Accuracy and clarity of flashbulb memories related to World War II. Journal of Experimental Psychology: General, 134, 242-257. doi:10.1037/0096-3445.134.2.242

BLUCK, S. (2003). Autobiographical memory: Exploring its functions in everyday life. Memory, 11, 113-123. doi:10.1080/741938206

BLUCK, S., \& ALEA, N. (2002). Exploring the functions of autobiographical memory: Why do I remember the autumn? In J. D. Webster \& B. K. Haight (Eds.), Critical advances in reminiscence work: From theory to application (pp. 61-75). New York: Springer.

Bluck, S., Alea, N., Habermas, T., \& Rubin, D. C. (2005). A TALE of three functions: The self-reported uses of autobiographical memory. Social Cognition, 23, 97-117. doi:10.1521/soco.23.1.91.59198

BluCK, S., \& Habermas, T. (2000). The life story schema. Motivation \& Emotion, 24, 121-147. doi:10.1023/A:1005615331901

Bohn, A., \& Berntsen, D. (2007). Pleasantness bias in flashbulb memories: Positive and negative flashbulb memories from the fall of the Berlin Wall among East and West Germans. Memory \& Cognition, 35, 565-577.

BREWER, W. F. (1986). What is recollective memory? In D. C. Rubin (Ed.), Autobiographical memory (pp. 25-49). Cambridge: Cambridge University Press.

BREWER, W. F. (1996). What is recollective memory? In D. C. Rubin (Ed.), Remembering our past: Studies in autobiographical memory (pp. 19-66). Cambridge: Cambridge University Press.

Brown, R., \& KulIK, J. (1977). Flashbulb memories. Cognition, 5, $73-$ 99.

BRUCE, D. (1985). The how and why of ecological memory. Journal of Experimental Psychology: General, 114, 78-90. doi:10.1037/0096 $-3445.114 .1 .78$

BruCE, D. (1989). Functional explanations of memory. In L. W. Poon, D. C. Rubin, \& B. A. Wilson (Eds.), Everyday cognition in adulthood and late life (pp. 44-58). New York: Cambridge University Press.

Byrne, C. A., Hyman, I. E., JR., \& ScotT, K. L. (2001). Comparisons of memories for traumatic events and other experiences. Applied Cognitive Psychology, 15, S119-S133. doi:10.1002/acp.837

Christianson, S.-Å. (1992). Emotional stress and eyewitness memory: A critical review. Psychological Bulletin, 112, 284-309. doi:10.1037/0033-2909.112.2.284

CoHen, G. (1998). The effects of aging on autobiographical memory. In C. P. Thompson, D. J. Herrmann, D. Bruce, J. D. Read, D. G. Payne, \& M. P. Toglia (Eds.), Autobiographical memory: Theoretical and applied perspectives (pp. 105-123). Mahwah, NJ: Erlbaum.

Collins, K. A., Pillemer, D. B., Ivcevic, Z., \& Gooze, R. A. (2007). Cultural scripts guide recall of intensely positive life events. Memory \& Cognition, 35, 651-659.

ConWAY, M. A. (1996). Autobiographical knowledge and autobiographical memories. In D. C. Rubin (Ed.), Remembering our past: Studies in autobiographical memory (pp. 67-93). Cambridge: Cambridge University Press.

Conway, M. A. (2003). Commentary: Cognitive-affective mechanisms and processes in autobiographical memory. Memory, 11, 217-224. doi: $10.1080 / 741938205$ 
Conway, M. A., \& Pleydell-Pearce, C. W. (2000). The construction of autobiographical memories in the self-memory system. Psychological Review, 107, 261-288. doi:10.1037/0033-295X.107.2.261

DAlgleish, T. (2004). Cognitive approaches to posttraumatic stress disorder: The evolution of multirepresentational theorizing. Psychological Bulletin, 130, 228-260. doi:10.1037/0033-2909.130.2.228

D'Argembeau, A., Comblain, C., \& Van der Linden, M. (2003). Phenomenal characteristics of autobiographical memories for positive, negative, and neutral events. Applied Cognitive Psychology, 17, 281294. doi: $10.1002 /$ acp. 856

D’Argembeau, A., \& Van der Linden, M. (2004). Phenomenal characteristics associated with projecting oneself back into the past and forward into the future: Influence of valence and temporal distance. Consciousness \& Cognition, 13, 844-858. doi:10.1016/j .concog.2004.07.007

Fivush, R. (1988). The functions of event memory: Some comments on Nelson and Barsalou. In U. Neisser \& E. Winograd (Eds.), Remembering reconsidered: Ecological and traditional approaches to the study of memory (pp. 277-282). New York: Cambridge University Press.

FredricKson, B. L. (1998). What good are positive emotions? Review of General Psychology, 2, 300-319. doi:10.1037/1089-2680.2.3.300

FREDRICKSON, B. L. (2001). The role of positive emotions in positive psychology: The broaden-and-build theory of positive emotions. American Psychologist, 56, 218-226. doi:10.1037/0003-066X.56.3.218

Fredrickson, B. L., \& Branigan, C. (2005). Positive emotions broaden the scope of attention and thought-action repertoires. Cognition \& Emotion, 19, 313-332. doi:10.1080/02699930441000238

Freud, S. (1952). A general introduction to psychoanalysis. New York: Washington Square Press. (Original work published 1920)

Glenberg, A. M. (1997). What memory is for. Behavioral \& Brain Sciences, 20, 1-55. doi:10.1017/S0140525X97000010

Horowitz, M. J. (2001). Stress response syndromes: Personality styles and interventions (4th ed.). Northvale, NJ: Jason Aronson.

Hyman, I. E., JR., \& FARIES, J. M. (1992). The functions of autobiographical memory. In M. A. Conway, D. C. Rubin, H. Spinnler, \& W. A. Wagenaar (Eds.), Theoretical perspectives on autobiographical memory (pp. 207-221). Dordrecht: Kluwer.

JAMES, W. (1950). Principles of psychology. New York: Dover. (Original work published 1890)

JANOFF-Bulman, R. (1992). Shattered assumptions: Towards a new psychology of trauma. New York: Free Press.

LeVIne, L. J., \& BLuCK, S. (2004). Painting with broad strokes: Happiness and the malleability of event memory. Cognition \& Emotion, 18, 559-574. doi:10.1080/02699930341000446

Levine, L. J., \& Pizarro, D. A. (2004). Emotion and memory research: A grumpy overview. Social Cognition, 22, 530-554. doi:10.1521/ soco.22.5.530.50767

Lishman, W. A. (1974). The speed of recall of pleasant and unpleasant experiences. Psychological Medicine, 4, 212-218.

McLean, K. C., \& Lilgendahl, J. P. (2008). Why recall our highs and lows: Relations between memory functions, age, and well-being. Memory, 16, 751-762. doi:10.1080/09658210802215385

NaIrne, J. S., \& PANDEIRAda, J. N. S. (2008). Adaptive memory: Remembering with a stone-age brain. Current Directions in Psychological Science, 17, 239-243. doi:10.1111/j.1467-8721.2008.00582.x

Nairne, J. S., Thompson, S. R., \& Pandeirada, J. N. S. (2007). Adaptive memory: Survival processing enhances retention. Journal of Experimental Psychology: Learning, Memory, \& Cognition, 33, 263 273. doi: $10.1037 / 0278-7393.33 .2 .263$

NeIsser, U. (1982a). Memory: What are the important questions? In U. Neisser (Ed.), Memory observed: Remembering in natural contexts (pp. 3-19). San Francisco: Freeman.

NEISSER, U. (1982b). Snapshots or benchmarks? In U. Neisser (Ed.), Memory observed: Remembering in natural contexts (pp. 43-48). San Francisco: Freeman.

NeLSON, K. (1993). The psychological and social origins of autobiographical memory. Psychological Science, 4, 7-14. doi:10.1111/j.1467-9280 .1993.tb00548.x

Pasupathi, M., Lucas, S., \& Coombs, A. (2002). Conversational functions of autobiographical remembering: Long-married couples talk about conflicts and pleasant topics. Discourse Processes, 34, 163-192. doi:10.1207/S15326950DP3402_3
Pillemer, D. B. (1992). Remembering personal circumstances: A functional analysis. In E. Winograd \& U. Neisser (Eds.), Affect and accuracy in recall: Studies of "flashbulb" memories (pp. 236-264). New York: Cambridge University Press.

Pillemer, D. B. (1998). Momentous events, vivid memories. Cambridge, MA: Harvard University Press.

Pillemer, D. B. (2001). Momentous events and the life story. Review of General Psychology, 5, 123-134. doi:10.1037/1089-2680.5.2.123

PILlemer, D. B. (2003). Directive functions of autobiographical memory: The guiding power of the specific episode. Memory, 11, 193-202. doi: $10.1080 / 741938208$

Ross, M., \& Wilson, A. E. (2002). It feels like yesterday: Self-esteem, valence of personal past experiences, and judgments of subjective distance. Journal of Personality \& Social Psychology, 82, 792-803. doi:10.1037/0022-3514.82.5.792

Ross, M., \& Wilson, A. E. (2003). Autobiographical memory and conceptions of self: Getting better all the time. Current Directions in Psychological Science, 12, 66-69. doi:10.1111/1467-8721.01228

Rubin, D. C. (2006). The basic-systems model of episodic memory. Perspectives on Psychological Science, 1, 277-311.

Rubin, D. C., Berntsen, D., \& Bohni, M. K. (2008). A memory-based model of posttraumatic stress disorder: Evaluating basic assumptions underlying the PTSD diagnosis. Psychological Review, 115, 9851011. doi:10.1037/a0013397

Rubin, D. C., Boals, A., \& Berntsen, D. (2008). Memory in posttraumatic stress disorder: Properties of voluntary and involuntary, traumatic and nontraumatic autobiographical memories in people with and without posttraumatic stress disorder symptoms. Journal of Experimental Psychology: General, 137, 591-614. doi:10.1037/ a0013165

Rubin, D. C., \& Schulkind, M. D. (1997). Distribution of important and word-cued autobiographical memories in 20-, 35-, and 70-yearold adults. Psychology \& Aging, 12, 524-535. doi:10.1037/0882 $-7974.12 .3 .524$

Rubin, D. C., \& Siegler, I. C. (2004). Facets of personality and the phenomenology of autobiographical memory. Applied Cognitive Psychology, 18, 913-930. doi:10.1002/acp.1038

Schlagman, S., Schulz, J., \& Kvavilashvili, L. (2006). A content analysis of involuntary autobiographical memories: Examining the positivity effect in old age. Memory, 14, 161-175. doi:10.1080/09658210544000024

Talarico, J. M., Berntsen, D., \& Rubin, D. C. (2009). Positive emotions enhance recall of peripheral details. Cognition \& Emotion, 23, 380-398. doi:10.1080/02699930801993999

Talarico, J. M., LaBAR, K. S., \& Rubin, D. C. (2004). Emotional intensity predicts autobiographical memory experience. Memory \& Cognition, 32, 1118-1132.

TAYLOR, S. E. (1991). Asymmetrical effects of positive and negative events: The mobilization-minimization hypothesis. Psychological Bulletin, 110, 67-85. doi:10.1037/0033-2909.110.1.67

TAYlOR, S. E., \& Brown, J. D. (1988). Illusion and well-being: A social psychological perspective on mental health. Psychological Bulletin, 103, 193-210. doi:10.1037/0033-2909.103.2.193

Tulving, E. (2002). Episodic memory: From mind to brain. Annual Review of Psychology, 53, 1-25. doi:10.1146/annurev.psych.53.100901.135114

Vaish, A., Grossmann, T., \& Woodward, A. (2008). Not all emotions are created equal: The negativity bias in social-emotional development. Psychological Bulletin, 134, 383-403. doi:10.1037/0033 $-2909.134 .3 .383$

VAN DER KOLK, B.A., \& FISLER, R. (1995). Dissociation and the fragmentary nature of traumatic memories: Overview and exploratory study. Journal of Traumatic Stress, 8, 505-525. doi:10.1007/BF02102887

Walker, W. R., Skowronski, J. J., \& Thompson, C. P. (2003). Life is pleasant - and memory helps to keep it that way! Review of General Psychology, 7, 203-210. doi:10.1037/1089-2680.7.2.203

Walker, W. R., Vogl, R. J., \& Thompson, C. P. (1997). Autobiographical memory: Unpleasantness fades faster than pleasantness over time. Applied Cognitive Psychology, 11, 399-413. doi:10.1002/(SICI)1099 -0720(199710)11:5<399::AID-ACP462>3.0.CO;2-E

Wilson, A. E., \& Ross, M. (2003). The identity function of autobiographical memory: Time is on our side. Memory, 11, 137-149. doi:10.1080/741938210

Winograd, E., \& Neisser, U. (EDS.) (1992). Affect and accuracy in 
recall: Studies of "flashbulb" memories. New York: Cambridge University Press.

WonG, P. T. P., \& WATT, L. M. (1991). What types of reminiscence are associated with successful aging? Psychology \& Aging, 6, 272-279. doi:10.1037/0882-7974.6.2.272

Wood, W.-J. (2006). The role of emotions in the functions of autobiographical memory (Doctoral dissertation, Concordia University, 2006). Dissertation Abstracts International, 66(11B), 6309.

\section{NOTE}

1. A folk high school [folkehøjskole] in Denmark is an institution of nonformal and continuing adult education, often with a dominance of creative and artistic topics, such as music, drama, and painting. A typical folk high school student is a young person who has finished ordinary high school and who wants to spend some time exploring a creative topic before beginning his or her college education.

\section{APPENDIX}

Examples of Memory Descriptions for Directive, Self-, and Social Memories From a Pilot Study

\section{Directive Memory (Female, 25 years)}

I was at a meeting with my parents and a social worker concerning whether I should continue to live at my parents' house. I was rather young, and my parents and I were not on good terms. We sat in my parents' home and at some point in the conversation, the social worker asked my mom if she really meant all the things she was saying about me, and she answered: "Yes!" She believed that I was a bad person, because of the things I had done. It made a strong impression, although it did not surprise me that she felt that way. It still affects me, and I always have to prove that I'm good enough — at least to myself.

\section{Directive Memory (Male, 27 years)}

When I first started partying with my friends, drinking alcohol and keeping an eye out for the girls, my dad said to me: "You should always be a gentleman and be able to face yourself in the mirror the following day." I had a great deal of respect for my dad, and for many years I would actually look in the mirror the morning after a night out, just to make sure that I was able to look myself in the eyes. Each time I did so, I appreciated the advice given to me by my dad. It gave me a feeling that I was behaving properly, and I really appreciated the advice - and did my best to live up to it.

\section{Self-Memory (Female, 24 years)}

I was very nervous, because I was starting a new job the next day. I was afraid that I wouldn't know what to do at all, and that the whole staff would think that I was a burden instead of a help. I was nervous all night, wishing that time would stop, and that the next day would never come. I think this memory tells me something about my identity, because it points out that I'm a very quiet girl that sometimes gets very nervous that I can't do what I'm supposed to do in a way that is satisfactory to other people.

\section{Self-Memory (Female, 25 years)}

It is the day when we are told whether we get admitted to the university that we have applied to. I remember sitting in the window waiting for the mail to arrive and it feels like a very long time. When the mail finally arrives, and I open the letter, I see that I have been accepted to the university that was number one on my list; I start to cry.

\section{Social Memory (Male, 27 years)}

I'm at this high school party and I see a girl with incredible hair. I compliment her and offer to buy her a beer. She doesn't seem that impressed with my attempts at being charming, and politely rejects my offer. It doesn't bother me so much. I'm pretty drunk, so I survive. Later in the evening: I'm still thinking of the girl, so I try to find her again. I succeed, and before the party has ended, we have kissed for the first time. This is the first meeting with the girl that is now my girlfriend.

\section{Social Memory (Female, 25 years)}

We are in the seventh grade gym class doing the long jump. When it's my turn, my friend is lying down on the track field and tells me to jump over him. When I do so, I hurt my knee pretty severely. I remember lying in the "sandbox" with my teacher's jacket covering my knee when several of the other students start to cry. A friend keeps me company and talks to me while we are waiting for the ambulance, and that friend is my boyfriend today. 